\title{
Corrosion Studies on Stainless Steel (FE6956) in Hydrochloric Acid Solution
}

\author{
Raphael Shadai Oguike \\ Corrosion Protection and Materials Science Laboratory, Department of Chemistry, Abubakar Tafawa Balewa \\ University, Bauchi, Nigeria \\ Email: oguike.raphael@yahoo.com
}

Received 7 June 2014; revised 24 July 2014; accepted 8 August 2014

Copyright (C) 2014 by author and Scientific Research Publishing Inc.

This work is licensed under the Creative Commons Attribution International License (CC BY).

http://creativecommons.org/licenses/by/4.0/

(c) (i) Open Access

\section{Abstract}

The effect of hydrochloric acid concentration on stainless steel (Fe6956) at temperature range $303-333 \pm 1 \mathrm{~K}$ has been studied using weight loss, thermometric and electrochemical polarization techniques. The corrosion rate of the stainless steel was found to be dependent on both temperature variation and acid concentration. The potentiostatic study showed that the active passive transition depends strongly on acid concentration while the weight loss measurements revealed that $2 \mathrm{M} \mathrm{HCl}$ at temperature $333 \mathrm{~K}$ had an appreciable corrosion rate which corresponds to $14.04 \times$ $10^{-3}$ reaction number (RN) got from thermometric monitoring. Arrhenius equation and transition state theory were used to calculate kinetic and thermodynamic parameter such as Ea, $\Delta \mathrm{H}^{*}$ and $\Delta \mathrm{S}^{*}$. Results obtained showed that corrosion reaction of $\mathrm{Fe} 6956 \mathrm{in} \mathrm{HCl}$ is spontaneous and there is good agreement between the data got from the techniques employed.

\section{Keywords}

Fe6956 Stainless Steel, Corrosion Rate, Hydrochloric Acid, Thermometric Measurement

\section{Introduction}

The all round viable characteristics of stainless steels for engineering works are directly credited to the indiscriminate selection of the steel in the process industries which result in corrosion failures. Stainless steel has a pleasing and aesthetic appearance with usage covering a wide range of steel types and grades for corrosion or oxidation resistant applications. The prerequisite for stainless steel is that they should have high corrosion resistance for a specified application or environment [1] [2]. Properties of stainless steel include structural efficiency, easy maintenance, high ductility, high cryogenic toughness, high work hardening rate, and improved fire resistance among others. Increasing competitive price of stainless steel could add to its advantages over the usage of 
other forms of steels. According to several authors, the excellent corrosion resistance of stainless steel in many aqueous solution results from its ability to protect itself from the corrosive environment via formation of a thin passive film [3]-[7] which consists of a mixture of iron and chromium oxides, with the hydroxide and watercontaining compounds located at the outermost region of the passive film while the chromium oxide enrichment is found at the metal/film interface [8]. This film varies in composition from alloy to alloy and also temperature dependent. For all stainless steel, this film is stabilized by chromium oxide and it is considered nonporous, insoluble, passive and self-healing when attacked [9]. Under conditions favorable to passivity, stainless steel has solution potentials approaching those of noble metals [10].

Hydrochloric acid is extensively used in acid cleaning, pickling of steel structures and descaling processes, as well as for drilling operations and oil well acidizing. These processes are normally accompanied by substantial loss of the metal to corrosion reaction. Hydrochloric acid next to sea water, remains the main source of the aggressive chloride ions and is capable of donating free chloride ions $\left(\mathrm{Cl}^{-}\right)$in an aqueous solution which causes material failure as a result of its attack on metals via corrosion [11]. Chloride ion is extremely electronegative, and therefore, very reactive with certain compounds and elements. This reactivity is part of its usefulness which is undermined by befouling where stainless steel is concerned. Although chloride is known to be the primary agent of pitting attack, it is not possible to establish a single critical chloride value for metals and alloys [12]. The corrosiveness of chloride ion concentration in solution can be greatly affected by the presence of various chemical species which might accelerate or inhibit corrosion reaction. However, the corrosion resistance of stainless steel is nevertheless better than most alloys. Various studies have been carried out to determine the corrosion behavior of stainless steel in acid and basic media as well as aqueous solutions contaminated with chloride $\left(\mathrm{Cl}^{-}\right)$ions which is known to cause pitting and crevice corrosion on metal surface [13]. Pitting is simply a breakdown of the passive layer followed by localized corrosion that produces pits, which causes perforation of steel vessels or pipes. This is mainly associated with microscopic heterogeneities in metal surface rather than macroscopic physical features of a component. Crevice corrosion is also a breakdown of the chromium oxide layer followed by localized corrosion but in contrast to pitting, it occurs at specific physical features where a surface is partly shielded and stagnant solution exists at an interface within the shielded area [14]. Bared metal surface sites become exposed to the corrodent after the breakdown of the passive film, leading to a sequence electrochemical reaction as the metal dissolves. Corrosion reaction is accompanied by conjugate anodic and cathodic process in which heat evolution is often predominant in strong acid and alkaline solutions [15].

This present study employs corrosion measurement techniques such as weight loss, thermometric and potentiodynamic polarization to monitor the effect of acid concentration on Fe6956 corrosion in hydrochloric acid solution in order to determine its viability in process industries. The weight loss method was carried out at different temperatures to study the effect of temperature on corrosion of Fe6956, while polarization method revealed the electrochemical behaviour of stainless steel in different $\mathrm{HCl}$ acid concentration. The thermometric measurements gave an insight to corrosion reaction by way of reaction number (RN). The dependence of corrosion rate on temperature and acid concentration was discussed using Arrhenius equation and transition state equation to calculate kinetic and thermodynamic parameters such as frequency factor (A), activation energy (Ea), entropy of activation $\left(\Delta \mathrm{S}^{*}\right)$ and enthalpy of activation $\left(\Delta \mathrm{H}^{*}\right)$. The chemical compositions (ppm) of Fe6956 are listed in Table 1 while corrosion rate $\left(\mathrm{K}_{\mathrm{CR}}\right)$ was calculated in millimeter penetration per year $\left(\mathrm{mmy}^{-1}\right)$ using Equation (1) [5]

$$
\mathrm{K}_{\mathrm{CR}}=\mathrm{k} \Delta \mathrm{W} / \rho \mathrm{AT}
$$

where $\mathrm{k}=$ unit of corrosion rate constant $\left(8.76 \times 10^{4} \mathrm{mmy}^{-1}\right)$;

$\Delta \mathrm{W}=$ weight loss in $\mathrm{mg}$;

$\rho=$ density of metal $\left(\mathrm{g} / \mathrm{cm}^{3}\right)$;

$\mathrm{T}=$ exposure time in hours;

$\mathrm{A}=$ area of working electrode $\left(\mathrm{cm}^{2}\right)$.

\section{Experimental}

\subsection{Material Preparation}

Stainless steel (Fe6956) composition given in Table 1 was obtained commercially from Advent research materials Ltd, Eynsham Oxford England OX294JA. The sheet was mechanically press-cut into $4.0 \times 4.0 \times 0.1 \mathrm{~cm}$ 
Table 1. Chemical composition (ppm) of stainless steel (Fe6956).

\begin{tabular}{ccccccccc}
\hline $\mathrm{C}$ & $\mathrm{Si}$ & $\mathrm{Mn}$ & $\mathrm{Ni}$ & $\mathrm{P}$ & $\mathrm{Cr}$ & $\mathrm{Mo}$ & $\mathrm{S}$ & $\mathrm{Fe}$ \\
\hline$<300$ & $<1000$ & $<2000$ & $<13,500$ & $<450$ & $<17,000$ & $<3000$ & $<300$ & Balance \\
\hline
\end{tabular}

working electrodes with a hole of $1 \mathrm{~mm}$ drilled at the upper edge of the coupons. These were used without further polishing but they were degreased in absolute ethanol, dried in acetone and further dried with hot air and then stored in moisture-free desiccator prior usage. Corrosive solutions were prepared from analytical BDH grade reagent using double distilled water. Fresh working electrodes and solutions were used for each test run. All computations were done using Origin Pro 8 Data analysis \& graphing workspace.

\subsection{Weight Loss Measurement}

In weight loss measurement, metal coupons were weighed before total immersion in graduated glass vessel having a total volume of $250 \mathrm{ml}$, while $200 \mathrm{ml}$ corrosive solution of $0.5,1.0,1.5$ and $2.0 \mathrm{M} \mathrm{HCl}$ were employed in each experiment. The reaction basin was placed in a thermostated water bath maintained at constant temperature 303, 313, 323 and $333 \pm 1 \mathrm{~K}$. The test coupons of Fe6956 were suspended with suitable glass hooks about $1 \mathrm{~cm}$ below the surface of the corrosive solution [16]. After three hours, the coupons were retrieved washed by immersion in distilled water, scrubbed with bristle brush, cleaned with ethanol, dried in acetone and further air dried and reweighed [17]. The difference in weight was taken as the weight loss (mg).

\subsection{Thermometric Measurement}

The stainless steel sheet was press cut to $4.0 \times 2.0 \times 0.1 \mathrm{~cm}$ and chemically degreased as described earlier. The measurement was carried out in a Dolvacpyrex flask covered with sheets of aluminum foil. The reaction vessel consist of $50 \mathrm{ml}$ of the acid put into the flask embedded in aluminum foil, corked with a Checktemp ${ }^{\circledR} 1$ digital thermometer in place. The metal coupon was introduced into the corrodent and quickly covered. The variation of temperature of the system was monitored with time and the reaction number (RN) is defined as [15]

$$
\mathrm{RN}\left({ }^{\circ} \mathrm{C} / \mathrm{min}\right)=\mathrm{T}_{\mathrm{m}}-\mathrm{T}_{\mathrm{i}} / \mathrm{t}_{\mathrm{m}}
$$

where $T_{m}$ and $T_{i}$ are the maximum and initial temperatures respectively, $t_{m}$ is time in minutes taken to attain the maximum temperature.

\subsection{Electrochemical Measurement}

An electrochemical cell with a three-electrode configuration was used for electrochemical measurements; Fe6956 coupon embedded in coad and having an exposed area of $1 \mathrm{~cm}^{2}$ was used as working electrode, a platinum electrode and a saturated calomel electrode (SCE) were used as counter and reference electrode respectively. The working electrode was grinded successively with metallographic emery paper of increasing fineness of up to 1000 grits, and then cleaned with distilled water, degreased with ethanol, and finally dried with warm air. Electrochemical experiment was performed by Potentiostat/Galvanostat model 263 using Power Suite software after the working electrode was immersed for 1800 seconds in aerated corrosive solution at open circuit potential [18]. The potentiodynamic polarization curves were obtained by scanning the potential of stainless steel from $-0.25 \mathrm{~V}$ to $1.6 \mathrm{~V}$ vs. SCE at a scan rate of $1 \mathrm{mV} / \mathrm{s}$.

\section{Results and Discussions}

The weight loss results and corrosion rates for Fe6956 corrosion in 0.5, 1.0, 1.5, and 2.0 $\mathrm{M} \mathrm{HCl}$ acid solution with temperature at 303, 313, 323, and $333 \pm 1 \mathrm{~K}$ are shown in Table 2. A close inspection revealed that Fe6956 greatly failed in $\mathrm{HCl}$ solutions. It can be seen that increase in either temperature or concentration of the acid resulted in increased corrosion rate. As shown in Figure 1, increase in temperature caused an increase in corrosion rate, also rise in acid concentration resulted in a significant increase in corrosion rate. These indicate that greater concentration of $\mathrm{Cl}^{-}$ions destroyed the passive films which tend to isolate the metal from the corrosive solution. Figure 2 shows the thermometric plot of temperature as a function of time. The thermometric measurement 
Table 2. Values of Fe6956 weight loss and corrosion rate in different concentrations of $\mathrm{HCl}$ at varying temperature.

\begin{tabular}{cccccccccc}
\hline Temp. (K) & \multicolumn{2}{c}{303} & \multicolumn{2}{c}{313} & \multicolumn{2}{c}{323} & \multicolumn{3}{c}{333} \\
\hline Conc. (M) & $\begin{array}{c}\text { Weight loss } \\
(\mathrm{mg})\end{array}$ & $\begin{array}{c}\text { Corrosion rate } \\
\left(\mathrm{mmyr}^{-1}\right)\end{array}$ & $\begin{array}{c}\text { Weight loss } \\
(\mathrm{mg})\end{array}$ & $\begin{array}{c}\text { Corrosion rate } \\
\left(\mathrm{mmyr}^{-1}\right)\end{array}$ & $\begin{array}{c}\text { Weight loss } \\
(\mathrm{mg})\end{array}$ & $\begin{array}{c}\text { Corrosion rate } \\
\left(\mathrm{mmyr}^{-1}\right)\end{array}$ & $\begin{array}{c}\text { Weight loss } \\
(\mathrm{mg})\end{array}$ & $\begin{array}{c}\text { Corrosion rate } \\
\left(\mathrm{mmyr}^{-1}\right)\end{array}$ \\
\hline 0.5 & 12.1826 & 2825.0629 & 21.75481 & 5044.7940 & 30.89183 & 7163.6073 & 33.35737 & 7735.3495 \\
1.0 & 30.1666 & 6995.4314 & 62.21875 & 14428.1091 & 66.42468 & 15403.4360 & 72.22596 & 16748.7137 \\
1.5 & 43.7996 & 10156.8323 & 73.24119 & 16984.1387 & 77.59215 & 17993.0971 & 112.2548 & 26031.1322 \\
2.0 & 60.4783 & 14024.5105 & 144.45192 & 33497.4275 & 150.6883 & 34943.6020 & 157.3598 & 36490.6779 \\
\hline
\end{tabular}

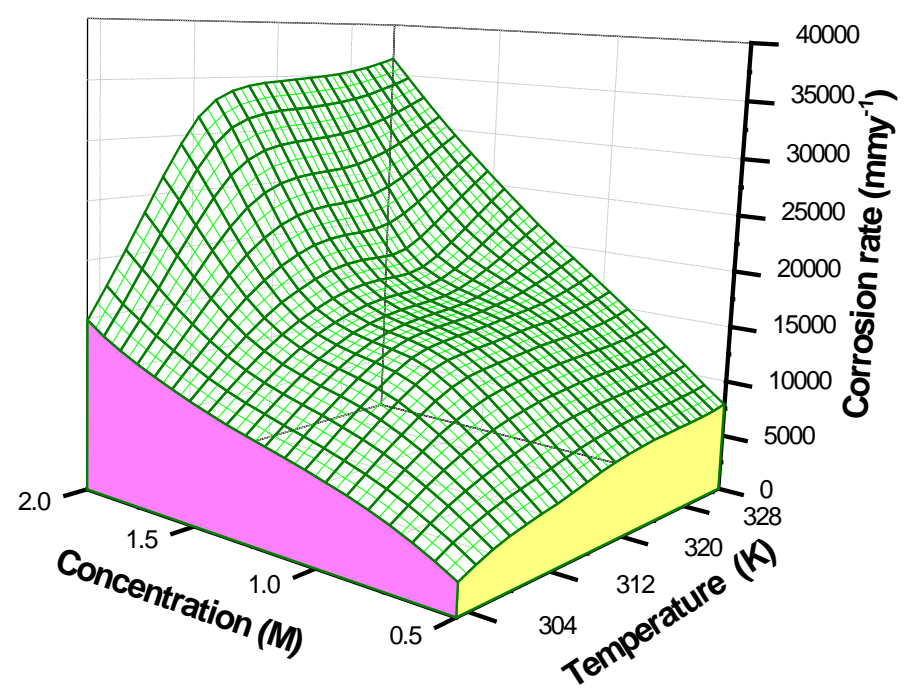

Figure 1. It shows the variation of corrosion rate as a function temperature and acid concentration.

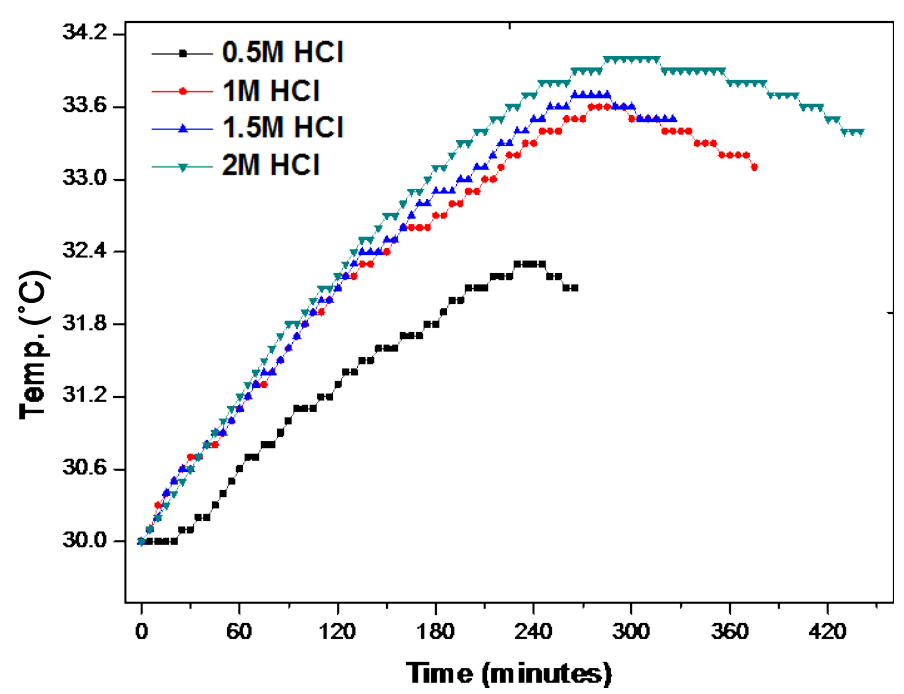

Figure 2. Thermometric plot of temperature as a function of time.

monitored increase in temperature with time and this varied insignificantly with time in minutes. All curves are characterized by a steady rise in temperature and a slight decrease after attaining a maximum values. This effect could be due to the presence of a passive film protecting the surface of the metal from the corrosive environment. 
The maximum temperature $34^{\circ} \mathrm{C}$ was reached after 285 min with $2 \mathrm{M} \mathrm{HCl}$ solution which corresponds to a reaction number of $14.04 \times 10^{-3}{ }^{\circ} \mathrm{C} / \mathrm{min}$. Reaction number (RN) values are known as a relative measure of retardation of the dissolution process [15]. Values of reaction number (RN), modified frequency factor (A), activation energy $\left(\mathrm{E}_{\mathrm{a}}\right)$, entropy of activation $\left(\Delta \mathrm{S}^{*}\right)$ and enthalpy of activation $\left(\Delta \mathrm{H}^{*}\right)$ are shown in Table 3.

The information about corrosion rate and kinetic parameters may be helpful in corrosion control. Activation parameters for most systems can be estimated either from Arrhenius equation (Equation (3)) or transition state theory (Equation (4)). Chemical kinetics includes investigation of how different experimental conditions can influence the rate of a chemical reaction and yields information about the reaction mechanism as well as construct mathematical models that can describe the character of a chemical reaction [19]. Corrosion rate data as a function of acid concentration can be used to show the rate dependence of hydrochloric acid concentration. The kinetic and thermodynamic parameters were calculated using Equations (3) and (4) respectively [19]

$$
\begin{gathered}
\mathrm{K}_{\mathrm{CR}}=\mathrm{A} \exp \left(-\mathrm{E}_{\mathrm{a}} / \mathrm{RT}\right) \\
\mathrm{K}_{\mathrm{CR}}=(\mathrm{RT} / \mathrm{Nh}) \exp \left(-\Delta \mathrm{H}^{*} / \mathrm{RT}\right) \exp \left(\Delta \mathrm{S}^{*} / \mathrm{R}\right)
\end{gathered}
$$

where $\mathrm{K}_{\mathrm{CR}}$ is corrosion rate, $\mathrm{A}$ is modified frequency factor (pre-exponential factor), $\mathrm{E}_{\mathrm{a}}$ is activation energy $\left(\mathrm{KJmol}^{-1}\right), \mathrm{R}$ is gas constant $\left(\mathrm{Jmol}^{-1} \mathrm{~K}\right), \mathrm{T}$ is absolute temperature $(\mathrm{K}), \Delta \mathrm{H}^{*}$, enthalpy of activation $(\mathrm{eV}), \Delta \mathrm{S}^{*}$ is entropy of activation $\left(\mathrm{KJmol}^{-1} \mathrm{~K}^{-1}\right)$, N, Avogadro's number (molecule $\cdot \mathrm{mol}^{-1}$ ) and $\mathrm{h}$, Planks constant (J·sec· $\mathrm{Mol}^{-1}$ ). The values of activation energies and frequency factors are evaluated by rearranging Equation (3) in form of straight line;

$$
\log \mathrm{K}_{\mathrm{CR}}=\log \mathrm{A}-\mathrm{E}_{\mathrm{a}} / \mathrm{RT}
$$

Figure 3 shows a linear plot of $\log K_{C R}$ versus $1 / T$ from which the values of $A$ and $E_{a}$ are evaluated from the intercept and slope respectively which are given in Table 3 . The obtained values of A increases with increase in acid concentration up to $1.5 \mathrm{M}$ and a sharp fall at $2 \mathrm{M}$ concentration while the values of $\mathrm{E}_{\mathrm{a}}$ decreased linearly with increase in acid concentration up to $1.5 \mathrm{M}$ and a noticeable decrease at $2 \mathrm{M}$. This indicates that at acid concentration greater than $1.5 \mathrm{M} \mathrm{HCl}$, the nonporous film which protects the steel gives way to pitting action of the chloride ions. Equation (4) can also be rearranged in form of straight line (Equation (6)) in order to obtain the values of enthalpy and entropy of activations. The rearranged equation is

$$
\ln \mathrm{K}_{\mathrm{CR}} / \mathrm{T}=\operatorname{lnR} / \mathrm{Nh} \mathrm{R}+\mathrm{RT}
$$

Figure 4 presents a straight line plot of $\ln K_{C R} / T$ versus $1 / T$ from these linear plots, the values of $\Delta H^{*}$ and $\Delta S^{*}$ are calculated from the slope and intercept respectively, which are given in Table 3 . The values of $0.5 \mathrm{M} \mathrm{HCl}$ was $-1.5768 \times 10^{-3} \mathrm{eV}$ for $\Delta \mathrm{H}^{*}$ and $-33.1254 \mathrm{KJmol}^{-1} \mathrm{~K}^{-1} \Delta \mathrm{S}^{*}$. Both values got for $\Delta \mathrm{H}^{*}$ and $\Delta \mathrm{S}^{*}$ is an indication of a spontaneous reaction for corrosion of Fe6956 in hydrochloric acid. These values decreased negatively with increase in acid concentration, which indicates that the corrosion reaction needs low energy to occur; a trend which agrees with the reaction number $(\mathrm{RN})$. The negative values of enthalpy of activation reflect the exothermic nature of stainless steel dissolution process. This could mean that the energy barrier of corrosion reaction decreases as acid concentration increases. The values of entropy were negative in all acid concentrations indicating a spontaneous anodic dissolution $\mathrm{Fe}=\mathrm{Fe}^{++}+2 \mathrm{e}$ and a corresponding cathodic reaction $2 \mathrm{H}^{+}+2 \mathrm{e}=\mathrm{H}_{2}$

\begin{tabular}{|c|c|c|c|c|c|}
\hline \multirow{2}{*}{ Conc. (M) } & \multicolumn{2}{|c|}{$\begin{array}{c}\text { Arrhenius equation } \\
\text { (Equation (1)) }\left(\mathrm{mmyr}^{-1}\right)\end{array}$} & \multicolumn{2}{|c|}{$\begin{array}{l}\text { Transition state theory } \\
\text { (Equation (2)) }\left(\mathrm{mmyr}^{-1}\right)\end{array}$} & \multirow{2}{*}{$\mathrm{RN}\left(\times 10^{-3}\right)$} \\
\hline & $A\left(d^{-1}\right)$ & $\mathrm{E}_{\mathrm{a}}\left(\mathrm{KJmol}^{-1}\right)$ & $\Delta \mathrm{H}^{*} \times 10^{-3}(\mathrm{eV})$ & $\Delta \mathrm{S}^{*}\left(\mathrm{KJmol}^{-1} \mathrm{~K}^{-1}\right)$ & \\
\hline $0.5 \mathrm{M}$ & 28839.6511 & 11.8 & -1.5768 & -33.1254 & 9.78 \\
\hline $1.0 \mathrm{M}$ & 61608.4099 & 11.6 & -1.5329 & -29.5235 & 11.67 \\
\hline $1.5 \mathrm{M}$ & 69816.8097 & 11.3 & -1.5436 & -28.8525 & 12.96 \\
\hline $2.0 \mathrm{M}$ & 23262.6935 & 9.5 & -1.4489 & -24.2262 & 14.04 \\
\hline
\end{tabular}
[20].

Table 3. Values of frequency factor $(A)$, activation energy $\left(E_{a}\right)$, entropy of activation $\left(\Delta S^{*}\right)$, enthalpy of activation $\left(\Delta H^{*}\right)$ and reaction number (RN) as a function of acid concentration. 


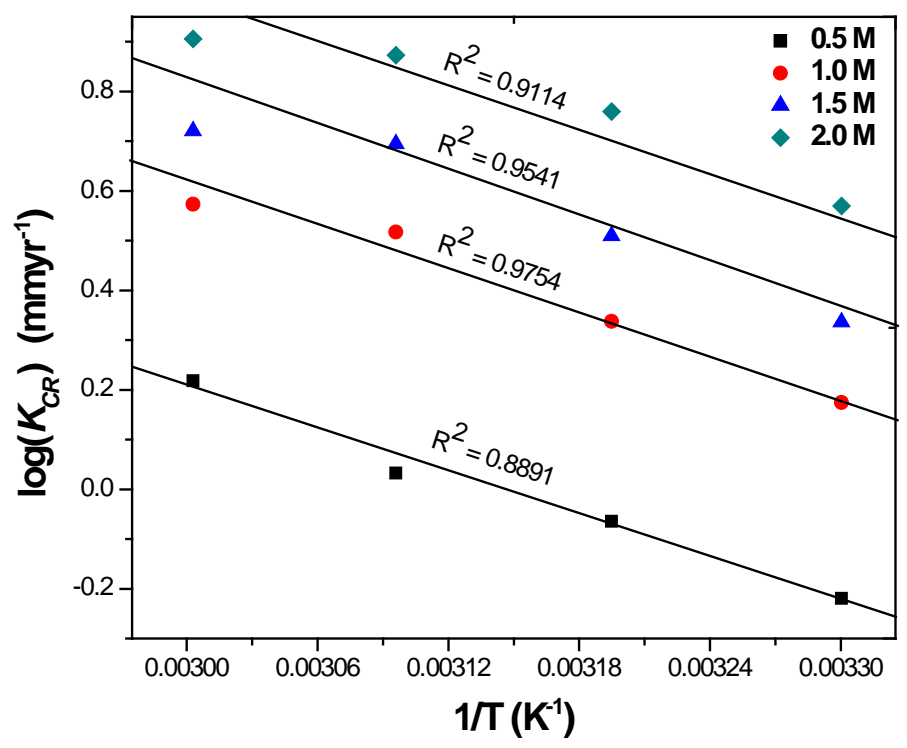

Figure 3. Arrhenius plot of corrosion rate for Fe6956 in different concentrations of $\mathrm{HCl}$.

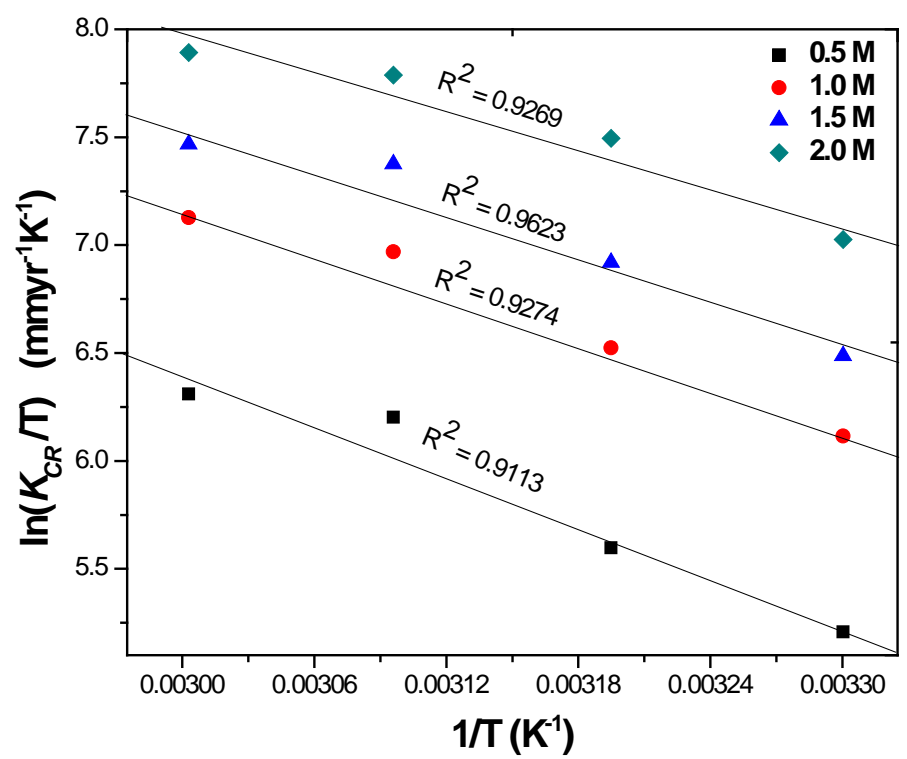

Figure 4. Transition state plot for the corrosion of Fe6956 as a function of $\mathrm{HCl}$ acid concentration.

According to Oguzie [20], the corrosion of metals in acidic solution is cathodically controlled by the hydrogen evolution reaction which occurs in two steps:

$$
\begin{gathered}
\mathrm{H}^{+}+\mathrm{e} \rightarrow \mathrm{H}_{\text {ads }} \\
\mathrm{H}_{\text {ads }}+\mathrm{H}_{\text {ads }} \rightarrow \mathrm{H}_{2}
\end{gathered}
$$

Yaro et al. [19], proposed the slowest step for the hydrogen evolution reaction as the recombination of adsorbed atoms to form hydrogen molecules (Equation (9c)). Hydrogen molecule evolution has received great attention from corrosion engineers and scientists because the amounts of hydrogen evolved by the cathodic reaction are proportional to the corroded amounts of iron. The following mechanisms can be proposed for hydrogen evolution reaction (HER) on electrodes in acidic media [21]: 


$$
\begin{gathered}
\mathrm{M}+\mathrm{H}_{3} \mathrm{O}^{+}+\mathrm{e}=\mathrm{MH}_{\mathrm{ad}}+\mathrm{H}_{2} \mathrm{O} \quad \text { (Volmer reaction) } \\
\mathrm{MH}_{\mathrm{ad}}+\mathrm{H}_{3} \mathrm{O}^{+}+\mathrm{e} \rightarrow \mathrm{M}+\mathrm{H}_{2}+\mathrm{H}_{2} \mathrm{O} \quad \text { (Heyrowsky reaction) } \\
\mathrm{MH}_{\mathrm{ad}}+\mathrm{MH}_{\mathrm{ad}}=2 \mathrm{M}+\mathrm{H}_{2} \quad \text { (Tafel reaction) }
\end{gathered}
$$

The cathodic reaction may have three different steps but the mechanisms do not occur as a single step but a combination of another; i.e. Volmer reaction (slow) with either Heyrowsky (faster) or Tafel (faster) reaction. If Volmer reaction is fast, Tafel and/or Heyrowsky reaction must be slow [22]. The conventional equation of chemical reaction kinetics could be useful at showing the rate dependence of $\mathrm{HCl}$ concentration by the following equation:

$$
\mathrm{r}=\mathrm{kC}^{\mathrm{n}}
$$

where $n$ is the order of reaction.

The above equation can be rearranged in a linear form in order to evaluate its kinetic constants. Equation (10) is rearranged thus:

$$
\ln \mathrm{r}=\ln \mathrm{k}+\mathrm{n} \ln \mathrm{C}
$$

Figure 5 shows linear plots of $\ln r$ versus $\ln C$, the values of $n$ and $k$ are evaluated from the slopes and intercepts respectively. Table 4 shows the values of kinetic parameters obtained in this study. The values of the rate constants $\mathrm{k}$ increased with increase in temperature while the order of reaction $\mathrm{n}$ decreased with increase in temperature. This is consistent with the findings of Yaro et al. [19] who studied mild steel corrosion in different concentrations of phosphoric acid.

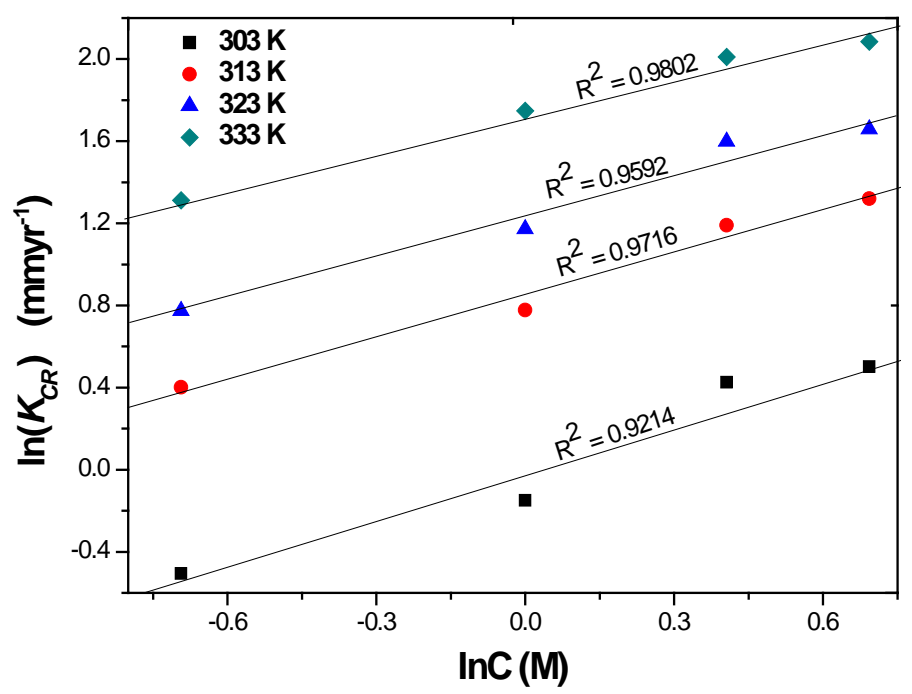

Figure 5. Conventional chemical reaction rate as a function of acid concentration at different temperatures.

Table 4. Values of kinetics parameters of rate reaction models as a function of different temperatures and polarization parameters at different concentrations of $\mathrm{HCl}$ solution.

\begin{tabular}{cccccc}
\hline & \multicolumn{2}{c}{ Kinetics parameters } & \multicolumn{3}{c}{ Polarization parameters } \\
\hline Temp. (K) & $\mathrm{k}, \mathrm{mmy}^{-1}$ & $\mathrm{n}$ & Conc. (M) & $\mathrm{E}_{\text {corr }}(\mathrm{mV} / \mathrm{SCE})$ & $\mathrm{I}_{\text {corr }}\left(\mathrm{mAcm}^{-2}\right)$ \\
\hline 303 & -0.0291 & 0.77742 & 0.5 & -27.529 & 77.14 \\
313 & 2.3173 & 0.6874 & 1.0 & -20.788 & 82.17 \\
323 & 3.3509 & 0.6773 & 1.5 & -18.439 & 99.75 \\
333 & 4.7032 & 0.57695 & 2.0 & -14.796 & 138.50 \\
\hline
\end{tabular}


Considering the transition state of the rate determining step, the obtained negative values of $\Delta \mathrm{S}^{*}$ implies a high orderly arrangement of the activated complex relative to the initial state. The obtained data from the varied temperature in which corrosion reaction occurred, suggests that corrosion rate can also be determined using activation energy and pre-exponential factor. A comparison of Figure 6 \& Figure 7 showed that the values of $E_{a}$ vary in the same way as the values of $\Delta \mathrm{H}^{*}$ while the obtained values of $\mathrm{E}_{\mathrm{a}}$ approximately agree with the literature of value of $\mathrm{E}_{\mathrm{a}}$ for stainless steel in hydrochloric acid.

\section{Potentiodynamic Polarization Measurement}

Stainless steel corrosion in aqueous acid system is mainly an electrochemical process. The potentiodynamic polarization behavior of Fe6956 was studied in relation to acid concentration. The potential was scanned automati-

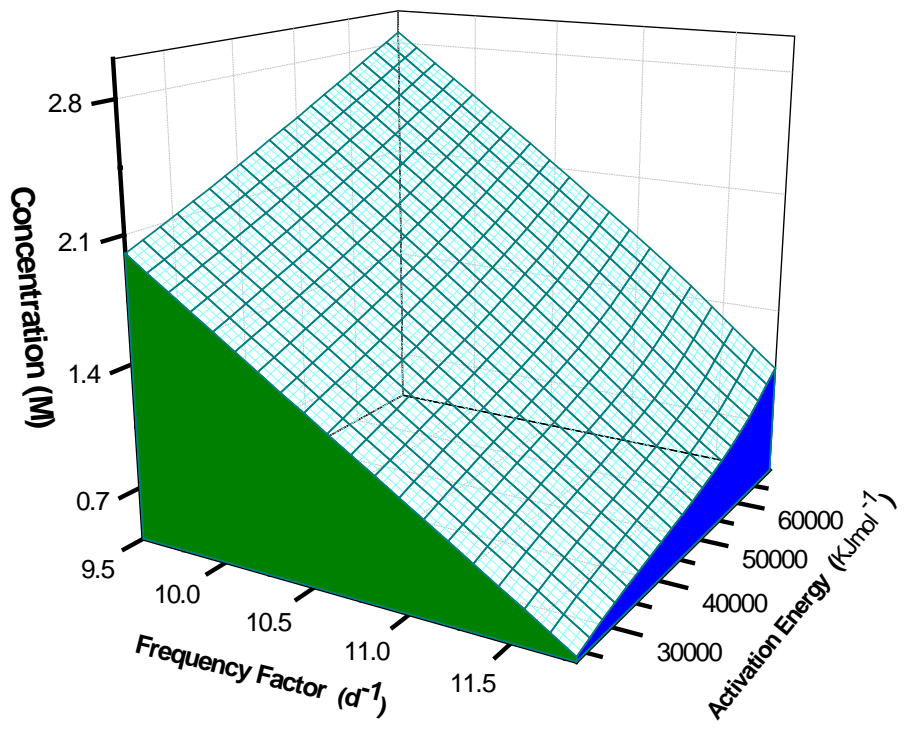

Figure 6. Arrhenius plot showing values of frequency factor (A) and activation energy $\left(E_{a}\right)$ as a function of different concentrations of $\mathrm{HCl}$.

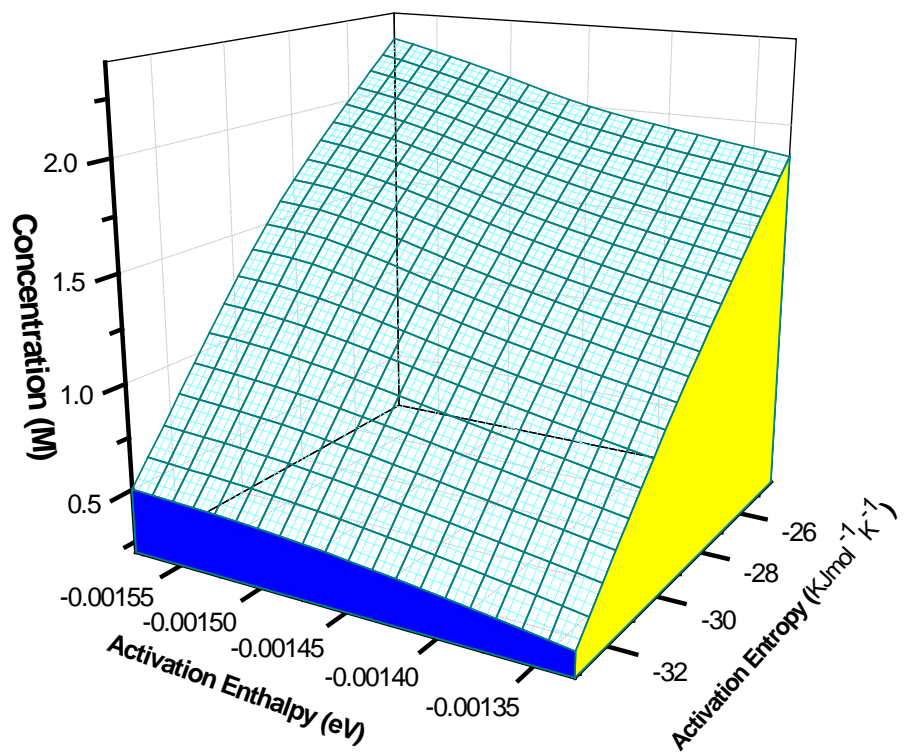

Figure 7. Transition state plot showing values of enthalpy of activation $(\mathrm{eV})$ and entropy of activation as function of acid concentration. 
cally at a rate which allowed the quasi-stationary state measurements. Prior to the potential scan the electrode was left under open-circuit condition in the respective acid solution for 30 minutes until a steady free corrosion potential was attained. Figure 8 shows linear sweep potentiodynamic traces for stainless steel in 0.5 , 1.0, 1.5, and 2.0 M HCl. From Table 4, $0.5 \mathrm{M} \mathrm{HCl}$ has the lowest corrosion current density and hence encountered the lowest corrosion rate. Current density $\left(\mathrm{i}_{\text {corr }}\right)$ increased with increase in concentration while corrosion potential decreased negatively indicating activation in the dissolution process of the surface oxide film, hence increase in dissolution of the steel. On studying the effect of acid concentration on stainless steel, it was noticed that the corrosion potential shifted slightly towards more positive potential (Figure 8) as acid concentration increased. The behavior indicates that the cathodic processes predominate over the anodic ones. This is characteristic of spontaneous attack of the chloride ions on the protective passive films associated with the steel and a reduction in its protective properties. The necessary electrons of the cathodic reaction are provided by the ionization of metal atoms (most probably Cr atoms) entering the oxide phase [23]. HER (9a-c) is reported to be generally the dominant local cathodic process in the corrosion of stainless steel in aqueous acidic solutions, via $\mathrm{H}^{+}$ion or $\mathrm{H}_{2} \mathrm{O}$ molecule reduction, respectively.

These anions were found to have a significant influence on the corrosion characteristics of stainless steel. It is clear from Figure 8 and Table 4 that metal wastage increases progressively with concentration of acid solution. Passivity was observed to prominent in $0.5 \mathrm{M} \mathrm{HCl}$ than in higher concentration. This passivation behaviour is attributed to the formation of passive oxide film on the metal surface which is corrosion resistant. This is in agreement with the corrosion rate results using weight loss and thermometric measurements. The critical current density was observed to have low value at $0.5 \mathrm{M} \mathrm{HCl}\left(77.14 \mathrm{mAcm}^{-2}\right)$, which also increased with increasing acid concentration. Increase in chloride ions reduced the potential range of the passive region, particularly by lowering the breakdown potential as a result of penetration and/or destruction of the passive film. Passivation is known not to be a constant state: it exists only in certain environments and/or under certain conditions which may be affected by slight changes in system as the case of increase in acid concentration. When passivity is destroyed, if it happens, stainless steel can fail by localized mechanisms such as pitting and crevice corrosion.

\section{Conclusion}

The corrosion of stainless steel (Fe6956) in acidic solution has been studied using weigh loss, thermometric and electrochemical polarization methods. Appreciable corrosion resistance of the tested Fe6956 coupons was found at $0.5 \mathrm{M} \mathrm{HCl}$ in all the tests, whose resistance was undermined with increase in both temperature and acid concentration. The corrosion rate was found to increase with increasing temperature and acid concentration. The obtained values for entropy and enthalpy of activation indicate the corrosion reaction of stainless steel is spontaneous in $\mathrm{HCl}$ solution. The corrosion polarization behaviour of Fe6956 showed active corrosion reactions

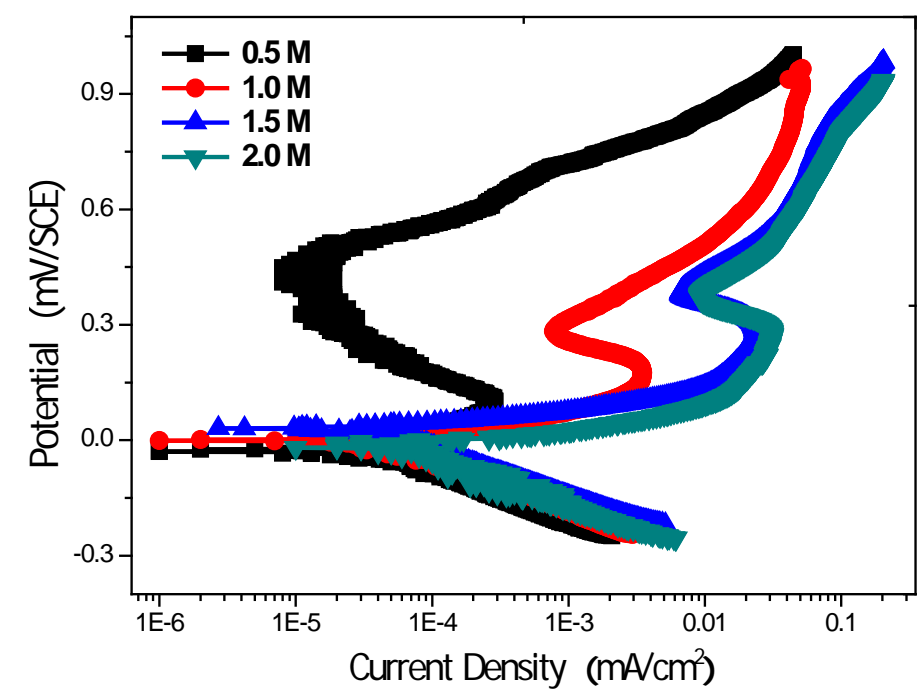

Figure 8. Potentiodynamic polarization curves for stainless steel in different concentrations of $\mathrm{HCl}$. 
behavior, however, shifts in polarization behaviour into active corrosion regions were seen with increase in acid concentration. The corrosion behaviour of Fe6956 at varying concentration as given by linear polarization measurements is in good agreement with that obtained from weight loss measurements and thermometric monitoring. However, the overall corrosion resistance performance of this alloy in the test environments can be rated as fair to good.

\section{Acknowledgements}

The author acknowledges the mentorship of E. E. Oguzie and staff of Corrosion Protection and Materials Science Laboratory, Department of Chemistry, Abubakar Tafawa Balewa University Bauchi for making available all necessary material for this study.

\section{References}

[1] Obiukwu, O.O., Opara, I.O. and Oyinna, B.C. (2013) Corrosion Inhibition of Stainless Steel Using Plant Extract Vernoniaamygdalina and Azadirachtaindica. Pacific Journal of Science and Technology, 14, 31-35.

[2] Fortuna, M.G. (1987) Corrosion Engineering. 3rd Edition, McGraw Hill, New York.

[3] Gasparac, R. and Martin, C. (2001) Investigations of the Mechanism of Corrosion Inhibition by Polyaniline. Polyaniline-Coated Stainless Steel in Sulfuric Acid Solution. Journal of The Electrochemical Society, 148, 4-11. http://dx.doi.org/10.1149/1.1354615

[4] Okpala, A.N. and Jombo, P.P. (2004) Corrosion Behavior of Stainless Steel in Seawater before and after Welding. Nigeria Journal of Engineering Research and Development, 3, 52-59.

[5] Sherif, El-S.M. (2011) Corrosion Behavior of Duplex Stainless Steel Alloy Cathodically Modified with Minor Ruthenium Additions in Concentrated Sulfuric Acid Solutions. International Journal of Electrochemical Science, 6, 22842298.

[6] Deepa Rani, P. and Selvaraj, S. (2012) Alcoholic Extract of Andrographis paniculata as Corrosion Inhibitor on Stainless Steel in Natural Sea Water Environment. International Journal of Chemical Research, 2, 6-18.

[7] Callister Jr., W.D. (2003) Materials Science and Engineering an Introduction. 6th Edition, John Wiley \&Sons, lnc., Hoboken.

[8] Loto, C.A. and Mohammed, A.I. (2005) Corrosion Resistance and Susceptibility of Type 304 Stainless Steels in Strong Acids. NSE Tech Trans., 40, 88-106.

[9] United States Environmental Protection Agency (2001) Report on the Corrosion of Certain Alloys. United States Environmental Protection Agency, Washington DC.

[10] Kruger, J. (2000) Basics of Corrosion Science and Engineering. McGraw-Hill, New York.

[11] Wang, R. and Kido, M. (2009) Influence of Input Power to Vibrator and Vibrator-to-Specimen Distance of Ultrasound on Pitting Corrosion of SUS304 Stainless Steel in 3.5\% Chloride Sodium Aqueous Solution. Corrosion Science, 51, 1604-1610. http://dx.doi.org/10.1016/j.corsci.2009.04.007

[12] Huang, Y.L., Cao, C.N., Lu, M. and Lin, H.C. (1993) Inhibition Effects of I- and I2 on Stress Corrosion Cracking of Stainless Steel in Acidic Chloride Solutions. Corrosion, 49, 644-649. http://dx.doi.org/10.5006/1.3316095

[13] Pardo, A., Otero, E., Merino, M.C., López, M.D, Utrilla, M.V. and Moreno, F. (2000) Influence of pH and Chloride Concentration on the Pitting and Crevice Corrosion Behavior of High-Alloy Stainless Steels. Corrosion, 56, 411-418. http://dx.doi.org/10.5006/1.3280545

[14] Roberge, P.R. (2000) Handdook of Corrosion in Engineering. 8th Edition, McGraw-Hill, New York.

[15] Gaber, A.L., Seliman, S.A. and Mourad, M. (1997) Thermometric Study of Inhibition of Aluminium Corrosion in Hydrochloric Acid Solution. Qatar University Science Journal, 17, 81-87.

[16] Muller, B. (2004) Citric Acid as Corrosion Inhibitor for Aluminium Pigment. Corrosion Science, 46, 159-167. http://dx.doi.org/10.1016/S0010-938X(03)00191-4

[17] Oguike, R.S., Chindo, I.Y. and Kolo, A.M. (2013) Corrosion Inhibition and Adsorption Behaviour of Parkiabiglobosa on Aluminium (AL1043) in Acidic Media. Journal of Research in Physical Sciences, 9, 31-39.

[18] ASTM (1984) Standard Practice for Conducting Potentiodynamic Polarization Resistance Measurements, ASTM International Canada G. 59-78.

[19] Yaro, A.S., Wael, R.K. and Khadom, A.A. (2010) Reaction Kinetics of Mild Steel in Phosphoric Acid. Journal of the University of Chemical Technology and Metallurgy, 45, 443-448.

[20] Oguzie, E.E. (2007) Corrosion Inhibition of Aluminium in Acidic and Alkaline Media Sansevieriatrifaciata Extract. 
Corrosion Science, 49, 1527-1539. http://dx.doi.org/10.1016/j.corsci.2006.08.009

[21] DeBerry, D.W. (1985) Modification of the Electrochemical and Corrosion Behavior of Stainless Steels with an Electroactive Coating. Journal of The Electrochemical Society, 132, 1022-1029. http://dx.doi.org/10.1149/1.2114008

[22] Myer Kutz and Associates (Ed.) (2002) Hand Book of Material Selection. John Wiley \& Sons, New York.

[23] Chen, Y.Y., Chou, L.B. and Shih, H.C. (2006) Factors Affecting the Electrochemical Behavior of Stress Corrosion Cracking of Alloy 690 in Chloride Environments. Materials Chemistry and Physics, 97, 37-49.

http://dx.doi.org/10.1016/j.matchemphys.2005.07.053 
Scientific Research Publishing (SCIRP) is one of the largest Open Access journal publishers. It is currently publishing more than 200 open access, online, peer-reviewed journals covering a wide range of academic disciplines. SCIRP serves the worldwide academic communities and contributes to the progress and application of science with its publication.

Other selected journals from SCIRP are listed as below. Submit your manuscript to us via either submit@scirp.org or Online Submission Portal.
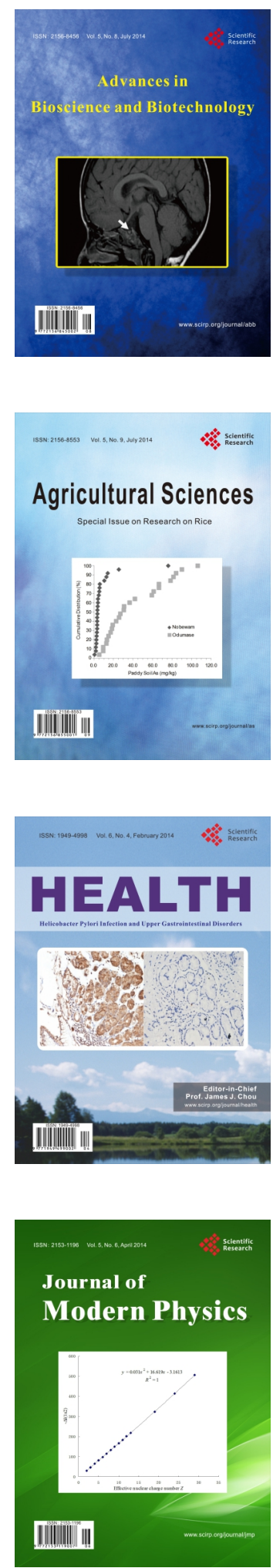
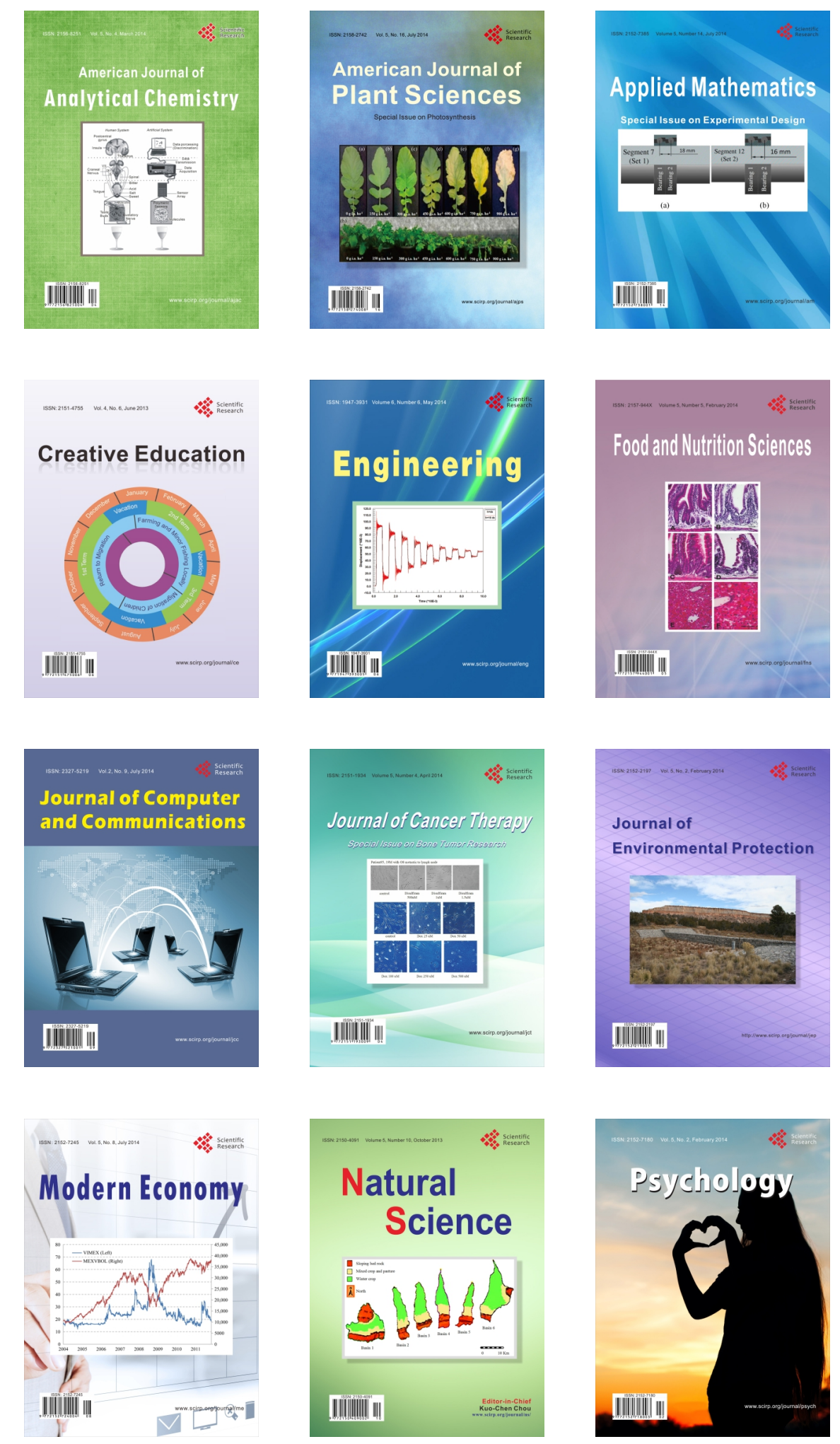